\title{
Muito mais do que pe(n)sam: percepçôes e experiências acerca da obesidade entre usuárias da rede pública de saúde de um município do Nordeste do Brasil*
}

\author{
| ${ }^{1}$ Maria Soraia Pinto, ${ }^{2}$ Maria Lúcia Magalhães Bosi |
}

Resumo: Investigação qualitativa exploratória com enfoque fenomenológico-hermenêutico crítico, visando a compreender percepçôes e experiências acerca da obesidade entre usuárias de um Centro de Saúde da Família. A estratégia metodológica adotada foi a articulação entre as entrevistas em profundidade e a observação livre junto a uma amostra intencional composta por oito mulheres obesas usuárias de um Centro de Saúde da Família localizado na cidade de Fortaleza, Ceará (Brasil). A categorização do material empírico indicou quatro eixos temáticos de análise:

1) Autopercepção do corpo; 2) Etno-etiologia da obesidade;

3) Estigma e suas repercussões nas distintas esferas da vida; 4) Trilhando os Caminhos da Cura. Apesar de reconhecerem o excesso de peso presente em seus corpos, sob outra terminologia, as mulheres não se identificam como obesas. Os sintomas clínicos e as dificuldades em desenvolver atividades diárias, bem como o discurso do profissional de saúde, foram importantes deflagradores da percepção da obesidade. Sobre essas mulheres pesa fortemente o estigma da obesidade, trazendo repercussões no seu dia a dia, influenciando as relaçôes sociais, familiares e de trabalho. As participantes consideram a obesidade uma doença passível de cura, sendo fortemente influenciada por suas próprias açôes. $\mathrm{O}$ conceito de cura para as depoentes não parece se vincular à obtenção de um corpo magro; dessa forma, visam à redução do uso de medicamentos e à possibilidade de realizar as atividades diárias. Para o acompanhamento deste grupo na atenção básica, se faz necessário agregar ao aspecto biomédico a perspectiva de quem vivencia a obesidade.
1 Mestre em Saúde Pública - Universidade de Fortaleza, Centro de Ciências da Saúde, curso de Ciências da Nutrição. Endereço eletrônico:: soraiapinto@yahoo.com.br

2 Doutora em Saúde Pública - Universidade Federal do Ceará, Faculdade de Medicina, Departamento de Saúde Comunitária. Endereço eletrônico: malubosi@ufc.br
Recebido em: 01/02/2010. Aprovado em: 10/05/2010. 


\section{Introdução}

A obesidade é um fenômeno complexo que se revela em seus aspectos mais imediatos e biológicos, acometendo uma parcela importante da população mundial. No entanto, além do excesso de gordura no corpo, a obesidade também se apresenta como experiência de enfermidade que engloba aspectos subjetivos, podendo ser vista como um atributo físico, percebido, interpretado e influenciado pelo sistema social e pela cultura.

A obesidade é um grave problema sócio-sanitário tanto em países desenvolvidos como naqueles em desenvolvimento. No Brasil, estudos demonstram que a população adulta vem apresentando um importante aumento na prevalência de excesso de peso. Dados da Pesquisa de Orçamentos Familiares (POF) de 2003 revelam que a obesidade afeta $8,9 \%$ dos homens adultos e 13,1\% das mulheres adultas do país. No Nordeste brasileiro, é possível acompanhar a tendência de crescimento da obesidade, em especial da obesidade feminina (JORDÃO; KAC, 2005). No entanto, a percepção da obesidade ultrapassa o cenário epidemiológico, revelando-se na vivência com o corpo. Várias conotaçóes, significados, importância e tratamentos foram impressas no corpo através dos séculos, nas diversas culturas e sociedades. Dessa forma, o corpo é representado, re-significado e passível de diferentes leituras consoante o contexto social e os diferentes campos do saber (BRASIL, 2006).

O corpo se revela assim um objeto polissêmico. Alguns especialistas da área da saúde o veem como depositário de processos biológicos indicadores de saúde ou doença para o indivíduo. Enquanto que para as ciências sociais o corpo é um reflexo da sociedade; ao corpo se aplicam discursos e práticas que estão na base de nossa vida social (FERREIRA, 1994).

Boltanski (1979) afirma que, para muitas mulheres das classes populares, o corpo pode se apresentar como condição para a produção do trabalho. No cotidiano de luta pela sobrevivência diária sobressaem duras e longas jornadas de trabalho, incluindo os afazeres domésticos e os cuidados com os filhos. Assim, o corpo tende a não ser percebido em toda sua plenitude, prevalecendo a dimensão instrumental voltada para a sobrevivência material. Dessa forma, o fenômeno da obesidade está situado em um escopo bem mais amplo e necessita ser apreendido a partir de uma visão multidimensional. Para tanto, impõe-se uma interlocução entre as ciências humanas e sociais e as ciências biológicas, a fim de alcançar uma aproximação mais adequada à complexidade do tema. 
Diante da escassez de estudos qualitativos acerca deste objeto, ao que se associa a inequívoca importância do tema como problema sócio-sanitário, o presente artigo tem como propósito explorar percepções e experiências acerca da obesidade entre usuárias da rede pública de saúde. Busca a compreensão do fenômeno obesidade para além de seus determinantes biológicos, percebendo-o em sua complexidade, incorporando a perspectiva e a experiência das mulheres que convivem com o fenômeno, apresentando assim a voz de quem vivencia o processo.

\section{Trajetória metodológica}

Dada a natureza e a complexidade do objeto de estudo, optamos por realizar uma investigação fundamentada na tradição qualitativa ancorada na vertente hermenêutica de tendência crítica (GODOY; BOSI, 2004). A vertente hermenêutica procura o significado da experiência enquanto produção humana capaz de expressar seu contexto. Busca-se, dessa forma, um processo de interpretação dialética, desvelando o significado atribuído pelas participantes à experiência da obesidade na materialidade concreta de suas vidas.

O estudo teve como espaço empírico o Centro de Saúde da Família - CSF Francisco Melo Jaborandi, situado no bairro São Cristóvão, periferia da cidade de Fortaleza (CE). Foram realizadas entrevistas ao longo de quatro meses de trabalho de campo, junto a mulheres adultas, adotando-se os seguintes critérios para composição da amostra intencional: mulheres entre 20 e 59 anos; com índice de massa corporal $>30 \mathrm{~m} / \mathrm{kg}^{2}$; com experiência de pelo menos cinco anos com o corpo obeso; residentes da cidade de Fortaleza e usuárias do referido centro.

Para a seleção das participantes, foram utilizados os prontuários médicos do ambulatório do CSF. Por se tratar de um estudo eminentemente qualitativo, não nos fixamos em questôes como "representatividade" ou "generalização". Adotamos como critério de suficiência o princípio da saturação teórica, sinalizando-nos a recuperação do modelo focalizado nesta investigação (BOSI, 2000). Foram entrevistadas oito mulheres, por uma das pesquisadoras responsáveis por este estudo, no período de novembro de 2008 a fevereiro de 2009. As entrevistas foram realizadas em único encontro com cada informante, no domicílio das mulheres, propiciando, assim, maior privacidade e comodidade. As entrevistas foram gravadas, com duração média de 60 minutos, verificando-se momentos de descontração e de emoção das mulheres ao relatarem algumas vivências em 
relação à obesidade. As entrevistas foram transcritas na íntegra, conservandose as expressões de linguagem utilizadas pelas entrevistadas, tendo em vista o estatuto fenomenológico do estudo.

A categorização do material empírico indicou quatro eixos temáticos, a partir dos quais foram traçadas as linhas de análise (interpretação): 1) Autopercepção do corpo; 2) Etnoetiologia da obesidade; 3) Estigma e as Repercussões nas distintas esferas da vida; 4) Trilhando os Caminhos da Cura. Cada eixo temático, por sua vez, foi desdobrado em diferentes dimensões.

O estudo teve aprovação do Comitê de Ética em Pesquisa da Universidade Federal do Ceará (UFC), sob o parecer de número 18/2008. Todas as informantes do estudo assinaram o termo de consentimento livre e esclarecido. $\mathrm{O}$ estudo seguiu todas as recomendaçôes da Resolução no196/96, que normatiza a pesquisa envolvendo seres humanos (BRASIL, 1996).

\section{Análise e discussão dos resultados}

As mulheres participantes do estudo situam-se entre 28 e 56 anos, com média de idade de 44 anos. Algumas referiram que realizavam atividades informais para complementar a renda da família. Os arranjos familiares eram núcleos do tipo mulher e cônjuge com filhos. Todas eram casadas ou mantinham união consensual. Apenas três mulheres relataram estar inseridas em postos de trabalho: costureira, técnica em enfermagem e comerciante, as demais eram donas de casa. Além disso, nenhuma delas assumia posto de chefe de família. Com relação aos valores de renda mensal, a média de remuneração familiar observada foi de um a dois salários mínimos. Quanto à escolaridade, metade das mulheres possuía o ensino médio e a outra metade o ensino fundamental incompleto.

As percepções e experiências com a obesidade, na perspectiva das mulheres do estudo, são apresentadas a partir dos temas descritos a seguir.

\section{Autopercepção do corpo}

No imaginário das mulheres obesas do estudo, prepondera a visão de que são "gordas", "gordinhas", "bem fortes", as mesmas não se percebem obesas, estando esse termo restrito a situações consideradas por elas como limite, caracterizando uma conotação negativa atribuída ao excesso de peso, presente no outro e não em si próprias. 
...por exemplo, eu se eu disparar na comida eu vou ser uma obesa; é vou disparar

As mulheres do estudo também revelaram que a deflagração da percepção do aumento do peso passou a existir após o surgimento de alguma complicação clínica, como a hipertensão, dislipidemia ou problema osteomuscular:

Antes eu não pensava nisso [peso], eu nem me olhava no espelho não, mas a ficha caiu quando tive esse problema da dor nos pés. (E3).

Os depoimentos indicam que as complicações clínicas representam uma das consequências mais imediatas do ganho de peso mais incômodas para as informantes. Os relatos confirmam que a percepção da obesidade está ligada a qualquer prejuízo na realização das atividades normais e às sensações desagradáveis como cansaço, dor, mal estar. Contudo, a obesidade parece afetar o corpo em sua totalidade, sendo difícil encontrar uma alteração física do organismo que não esteja atrelada ao excesso de peso.

Atrapalha tudo [o peso], o cansaço, qualquer coisa que eu faço eu fico cansada, se eu não me sentar me dá aquela moleza, aquele suor...a pressão que baixa. (E2)

Para Boltanski (1979), a atenção prestada ao corpo pelas classes sociais populares pode ser menos frequente. Particularmente neste grupo, o uso do corpo pode compreender uma visão mais utilitária, fruto da importância da força física nas ocupações desempenhadas. Dentro desta perspectiva, para muitas mulheres das classes populares o corpo pode se apresentar como condição para a produção do trabalho. No cotidiano de luta pela sobrevivência diária, incluindo os afazeres domésticos e os cuidados com os filhos, o corpo tende a não ser percebido em toda sua plenitude. Dessa forma, o corpo obeso parece ser julgado como "pesado" e, portanto, menos ágil. Nesse aspecto, o corpo magro passa então a ser valorizado.

Outra dimensão apontada nos relatos diz respeito à relação médico-paciente na determinação da obesidade por parte das mulheres do estudo. Torna-se evidente o papel do profissional de saúde na regulamentação do corpo:

Ele [médico] disse que meu peso tava muito acima e eu procurasse fazer uma dieta, baixar mais, que talvez a dor que eu sentia do joelho, a das pernas, o mal estar, porque eu sinto muito cansaço ele disse que pode ser por causa do peso. (E8)

Dessa forma, o saber dessas mulheres, pelo menos em parte, parece ser dependente do saber médico. No domínio da doença e da relação com o corpo, podemos retomar o trabalho de Boltanski (1968). O autor defende que o princípio 
explicativo do pensamento de senso comum sobre a doença reside, em particular, nas "classes baixas", no efeito de legitimidade produzido pelo discurso médico e na distância social que separa o médico e o doente. $\mathrm{O}$ discurso de senso comum parece, portanto, desprovido de autonomia, constituído, nas palavras do autor "de materiais fragmentários e heteróclitos, palavras mal-entendidas e frases em pedaços, arrancadas do discurso do médico" (BOLTANSKI, 1968, p. 81).

Godoy e Bosi (2004) também apresentam a relação médico-paciente, resgatando a influência do modelo biomédico nesta relação de poder implícita entre esse binômio, que segundo as autoras se expressa pela intervenção sobre o corpo físico do outro, desconsiderando seus desejos e emoções, privilegiando aspectos orgânicos sobre os emocionais. A desqualificação do cuidado do profissional de saúde (médico) durante o diagnóstico de obesidade de uma usuária transparece na seguinte situação:

Foi eu nunca me esqueci, naquela hora eu dei aquele baque assimparece que a mulher [médica] me deu foi uma facada, eu voltei pra casa triste com aquilo... Ela tinha me falado que tava bichado devido que tava com pressão alta, colesterol alto, triglicerídeo alto, aí ela usou essa expressão você ta "bichada". Pra mim aquela palavra "bichada" pesou muito eu sai pra casa assim triste, mas aí foi ela já me encaminhou para endocrinologia já rapidinho eu fiquei impressionada já logo fui correndo... (E1)

É válido ressaltar que o cuidado para com o outro seja concretizado através de atitudes de respeito, escuta e acolhimento dentro das especificidades, singularidades dos sofrimentos vivenciados. Uma nova atitude de cuidado para com o paciente se faz necessária na rede pública, atitude que proporcione o encontro e o diálogo com a alteridade (CARVALHO; FREIRE; BOSI, 2009).

\section{Etnoetiologia da obesidade}

Todas as mulheres do estudo declararam que apresentavam, quando mais jovens, um peso bem inferior e considerado adequado pela classificação da OMS (1995). Dessa forma, durante as entrevistas procuramos compreender de que forma esse excesso de peso foi se conformando a partir da perspectiva das mulheres. $\mathrm{Na}$ busca de uma explicação para o aumento de peso as mulheres identificam o uso de medicamentos como polivitamínicos e contraceptivos orais $(\mathrm{CO})$, como demonstrado nas afirmações abaixo:

Foi aí naquele momento eu querendo adquirir um peso maior né, eu danei tomando vitamina [polivitamínico]...um ano, 3 vezes ao dia... Não sei se foi a partir daí, porque logo em seguida eu passei a engordar. Aí nunca mais eu parei. (E1) 
Um estudo de revisão utilizando as bases bibliográficas Central, Medline, Embase, Popline e Lilacs realizado por Gallo et al. (2004), avaliou a associação entre o uso de $\mathrm{CO}$ e mudança de peso corporal. Os autores concluíram que as evidências disponíveis são insuficientes para determinar o efeito dos contraceptivos sobre o peso. Mito ou verdade, o fato é que, na perspectiva de todas as oito mulheres entrevistadas no estudo, o uso prolongado dos contraceptivos representou uma forte influência no aumento do peso corporal.

A alimentação excessiva também foi relatada pelas depoentes como causa da obesidade, duas mulheres declararam que consideravam o ganho de peso decorrente da maior ingestão alimentar e todas as entrevistadas relataram o consumo exagerado de alimentos.

Ah eu comia bem também,...comia era dentro de uma bacia [risos]. (E3)

Era o prato cheio mesmo, completo de tudo, eu gosto de farinha, gostava muito de macarrão, feijão, tudo completo, eu gostava de comer bem pra ficar bem satisfeita. (E2)

Essa dimensão nos remete à questão imediata quando se analisa a obesidade, qual seja, o aumento da ingestão calórica, levando ao acúmulo de gordura no corpo. As práticas alimentares das mulheres do estudo revelam um consumo de alimentos ricos em açúcares, gorduras e cereais, as preparaçōes mais comuns são ricas em gorduras (frituras), e menor contribuição de legumes e hortaliças nas dietas analisadas; associado a esse quadro ainda nos deparamos com o aumento do consumo de refrigerantes.

Há evidências de que o perfil alimentar da população brasileira apresentou excessivas mudanças nos últimos trinta anos. Inquéritos nacionais realizados pelo IBGE entre os anos de 1974 e 2003, ainda que limitados, nos apresentam ilustrativamente a tendência do padrão de consumo alimentar e valor nutricional da dieta utilizada pela população brasileira. Em se tratando da distribuição de macronutrientes, houve uma diminuição na participação relativa de carboidratos totais e complexos (61,66\% para 55,9\%) próximo ao limite inferior recomendado, ao passo que a participação dos lipídios aumentou de 25,7 para 30,5. Dessa forma, percebemos que a dieta do brasileiro vem paulatinamente substituindo carboidratos por gorduras, concorrendo para uma dieta mais calórica (BRASIL, 2006).

Algumas situações, aglutinadas em nosso estudo na dimensão passagens da vida das depoentes, foram consideradas por elas como deflagradoras do aumento 
corporal, dentre elas destacamos: o casamento, a gravidez, sofrimentos, em especial devido a doenças na família e perdas de entes queridos. As mulheres associaram o ganho de peso com duas passagens importantes de suas vida: o casamento e o nascimento de seus filhos.

Depois da gravidez a diferença é grande, tem muita diferença, nunca que a gente fica com mesmo corpo. (E1)

As informações fornecidas pelas mulheres na presente investigação são consonantes a alguns estudos qualitativos encontrados na literatura (TEIXEIRA, 2003; FERREIRA, 2005; PINTO, 2007). Esses estudos destacam que o casamento, a gravidez e o nascimento dos filhos apresentam-se como eventos importantes na gênese da obesidade, sendo repetidamente abordados pelas colaboradoras dos referidos estudos.

\section{Estigma e as repercussões nas distintas esferas da vida}

O terceiro tema que emergiu das entrevistas, sugere uma trama complexa relacionada à vivência com o excesso de peso associada ao estigma atribuído às mulheres do estudo permeando vários aspectos da vida dessas informantes. Durante a análise desta temática, percebemos que as mulheres entrevistadas apresentavam situações nas quais o estigma da obesidade se fazia presente trazendo repercussões no seu dia a dia, influenciando as relações sociais, familiares e de trabalho.

A estigmatização da obesidade causa prejuízos ao bem-estar social e psicológico dessas mulheres. As relações sociais são fortemente influenciadas por esse fenômeno. As informantes referiram que o excesso de peso contribuiu com a restrição de algumas atividades sociais, como sair com a família, ir à praia ou visitar amigos e parentes. Esse retraimento social parece estar ligado à percepção negativa que as mulheres têm de seus corpos, ressoando no estigma a eles relacionado, o que pode consequentemente levar ao isolamento dificultando a interação social deste grupo e mesmo agravá-lo ou cronificá-lo.

$\mathrm{O}$ obeso passa a ser estigmatizado na sociedade contemporânea, em vários aspectos da vida, aspecto que se intensifica à medida em que há uma expectativa crescente de que o ser humano magro ("sarado") é saudável, belo e importante. É nessa perspectiva que Goffman (1988) afirma que só há estigma quando há expectativa social de pelo menos um dos atores envolvidos numa relação. Dessa forma, é possível compreender que um atributo que estigmatiza alguém não é em 
si mesmo nem honroso nem desonroso, mas é a atitude e a relação que as pessoas

tomam em relação à marca corporal que atribui um valor. $\mathrm{O}$ estigma, nessa perspectiva, é uma relação entre atributo e estereótipo (o que sou/o que tenho - o que esperam de mim).

O pessoal quando vê uma gorda de longe, como eu te digo, por exemplo: Lá vem a Maria e a mãe dela, não, o pessoal não diz assim, diz: lá vem a Maria e a gorda, aquela mulher gorda. Pessoal até diz que gorda não tem nome, perde até o nome; é gorda, é gorda. (E4)

As pessoas obesas parecem ser mais vulneráveis à discriminação do que outros grupos. Para Wang e colaboradores (2004), ao contrário do que ocorre com outros grupos minoritários, as atitudes negativas para indivíduos com excesso de peso são aceitas e até mesmo incentivadas. As pessoas obesas frequentemente relatam que são ridicularizadas em público, por exemplo, sendo abordados por desconhecidos em mercearias, que tecem comentários sobre suas escolhas alimentares ou que as repreendem em restaurantes por comerem a sobremesa.

A vergonha do corpo expressa por algumas mulheres do estudo refletem também em alguns discursos de menor valia acerca delas próprias. Percebemos, em algumas falas, que as mulheres carregam concepçóes do obeso com desvalia, seja na aparência ou na "falta de força de vontade" para mudar. Além disso, como ressaltam os autores Lewis e Puymhroeck (2008), o grupo com obesidade possui preconceito em relação a si mesmo e com um outro "igual" e em suas relaçôes interpessoais. A experiência do preconceito vivida pelo obeso para consigo espelha uma tentativa de, por um lado, excluir de si mesmo sentimentos indesejados e, por outro, estampar a máscara social, que busca esconder e invalidar os potenciais das pessoas que discrimina. Dessa forma, o "outro- gordo" representa frequentemente o papel de espelho, tornando-se alvo dos sentimentos de baixa estima, de desvalia e de discriminação. Esse é um mecanismo de introjeção-projeção, concernente aos estudos da Psicologia, ou seja, um reflexo de auto-imagem projetada no outro (GASPAR, 2003).

eu fico impressionada que tem gente na praia mais gorda que eu e fica de fio dental, [risos] misericórdia [...], eu que fico com vergonha, eu não uso. Eu não tomo banho não. (E8)

Um aspecto importante para as participantes do nosso estudo diz respeito ao aspecto familiar: as depoentes retratam a presença do apoio familiar, no entanto, os relatos também indicam que os familiares contribuem para a disseminação do estigma. Algumas falas ilustram essas afirmativas: 
... dentro de casa mesmo, às vezes eu sinto assim que meu filho tem muita vontade que eu seja mais magra para me arrumar para sair do lado dele mais light, em casa eu já senti isso. (E2)

O estigma enfrentado por essas mulheres também parece ser disseminado no próprio entorno familiar, ainda que aparentemente as falas não demonstrem qualquer sentimento negativo em relação aos familiares. As repercussões na esfera familiar das colaboradoras do estudo destacam a importância de incluir a família nos programas de assistência e acompanhamento das mulheres obesas.

\section{Trilhando os caminhos da Cura}

A literatura médica é extensa quanto aos diferentes tratamentos para a obesidade; existem várias alternativas terapêuticas que, combinadas, conseguem significativas perdas de peso. Entre as estratégias utilizadas, os estudos destacam: as dietas de baixas e muito baixas calorias, a psicoterapia, a terapia comportamental, o exercício físico, e o uso de medicamentos que atuam no controle e regulação da adiposidade corporal (MANCINI; HALPERN, 2000). No escopo desta última temática, as dimensões do percurso terapêutico seguido pelas mulheres do estudo e a perspectiva de cura emergiram e permearam as falas.

Durante as entrevistas, as mulheres do estudo invariavelmente destacavam o percurso terapêutico trilhado. Impulsionadas por familiares, amigas ou profissionais de saúde, as mulheres submetiam-se às mais diferentes modalidades de tratamento do excesso de peso. Essa busca pela perda de peso transitava entre as dietas da moda, acompanhamento médico e o uso de medicamentos.

\footnotetext{
...tudo que era coisa que o pessoal me ensinava eu tomava, se a pessoa falasse, eu já tava fazendo. Cheguei a fazer a dieta da sopa, inclusive (risos) tô até com ela ali, que foi adquirida lá do hospital do coração, dizem que foi adquirida lá né, porque dizem que foi feita pra perder peso, pra perder gordura, eu tomei ela também. (E1)
}

A característica central da situação cotidiana da vida do indivíduo estigmatizado está na possibilidade de sentir-se aceito. Diante da angústia provocada pelas situações nas quais o estigmatizado é exposto, principalmente diante da falta de aceitação social, ele procura continuamente corrigir o seu problema. É comum, portanto, os gordos se lançarem em busca de cirurgias plásticas e bariátricas, exercícios físicos extenuantes e excessivos, dietas rigorosas e utilização de medicamentos para emagrecimento, sem prescrição médica. Em geral, esses recursos não provocam modificações significativas na vida dessas pessoas (MATTOS, 2008). 
O percurso terapêutico trilhado fez com que essas mulheres se submetessem aos diferentes tratamentos. Abordaremos a seguir a concepção de cura desejada pelas mulheres do estudo. Para as depoentes, a obesidade é uma doença que tem cura. Essa percepção de que a obesidade é uma enfermidade surge nos relatos a seguir:

Eu acho que é doença sim, é porque não é uma coisa normal não, e eu acho que tem cura pelo fato de você voltar ao normal perder aquele peso e manter sempre ali [...], mas se você se desleixar logicamente que vai voltar tudo de novo, aí... não vai valer de nada, mas é como eu to dizendo, que tem cura, mas se você mesmo quiser. (E2)

A expressão de cura entre as colaboradoras do estudo está ligada aos conceitos de autocontrole, força de vontade e perseverança. Para as entrevistadas, a cura é fortemente influenciada por suas próprias açoes e está veiculada aos benefícios à saúde.

É válido destacarmos que o conceito de cura para essas mulheres não parece está ligado à obtenção de um "corpo sarado"; ao contrário: as mulheres desta investigação não almejam o ideal de peso valorizado pela mídia. O peso considerado aceitável para o grupo de mulheres do estudo está relacionado ao peso que as torne aptas a realizar suas atividades diárias, que proporcione a redução no uso de medicamentos. Os discursos não parecem implicar necessariamente na busca do modelo hegemônico de corpo magro, como ideal de beleza. As mulheres do estudo buscam certo "padrão de normalidade" e, dessa forma, sentirem-se mais aceitas pela sociedade.

É legítimo refletir sobre o atendimento dispensado a essass mulheres. A obesidade tratando-se de um fenômeno multifatorial requer acompanhamento que compreenda o indivíduo em sua singularidade. Teixeira (2003) enfatiza que se faz necessário ser oferecida uma assistência especializada, onde esse grupo de usuárias seja considerado como seres humanos integrais, contando com escuta qualificada e atuação diferenciada para melhor atender ao grupo.

\section{Conclusão}

A obesidade é um fenômeno complexo que tem acometido na contemporaneidade parcela importante da população mundial. Os dados apresentados na revisão bibliográfica deste estudo destacam o crescimento histórico na prevalência desta enfermidade no Brasil. Nesse contexto epidemiológico, vale destacar que a prevalência do excesso de peso no país tem sido mais significativa entre a população feminina, adulta e nos estratos de menor renda. 
A complexidade desse fenômeno no universo feminino se revela para além dos dados epidemiológicos. O material discursivo nos revela que a experiência da obesidade expressa nos depoimentos ultrapassa a amplitude de seus corpos e nos revela que as mesmas são muito mais do que pesam. São mulheres que vivenciam um fenômeno e toda sua multidimensionalidade. A realização deste trabalho propiciou captar a riqueza interativa entre sujeito e objeto, fato somente possível devido à natureza qualitativa do estudo.

Os resultados demonstram que a obesidade encontrada nas mulheres do estudo, através da classificação biomédica do índice de massa corpórea superior a $30 \mathrm{~kg} / \mathrm{m} 2$, não reflete a percepção que as mesmas apresentam sobre seus corpos. As mulheres não se classificam como obesas e parecem mais inclinadas a adotar palavras como gordas ou gordinhas, eufemismos que permeiam seus discursos. $\mathrm{O}$ termo obesa reveste-se de uma conotação negativa e representa um estágio de agravamento no qual as mulheres ainda não se reconhecem. Outro ponto relevante diz respeito à influência do discurso médico na percepção de corpo das depoentes.

A pesquisa mostrou que a gênese da obesidade decorre de múltiplos determinantes. Na perspectiva das mulheres, a etiologia do ganho de peso ocorreu durante a vida adulta e as mesmas destacam como principais: o uso de medicamentos; o excesso alimentar; acontecimentos da vida e sofrimentos vivenciados pelas mesmas.

Sobre as mulheres de nosso estudo "pesam" não apenas a gramatura de seus corpos, mas também os estigmas e discriminações atribuídos à sua aparência. O estigma se traduz em olhares recriminadores, insultos, comentários jocosos e significa a impossibilidade de inserção no mercado de trabalho formal. O estigma da obesidade permeia as distintas esferas da vida das informantes do estudo, principalmente em suas relaçōes interpessoais, sociais, familiares e de trabalho. Além disso, ele atinge a dimensão do próprio grupo das informantes, em relação a si mesmo e ao outro igualmente obeso. Percebemos que as informantes do estudo transitam entre vítimas e algozes do estigma da obesidade, seja como um mecanismo de projeção ou de proteção.

Finalmente, emergiu das falas de todas as depoentes o percurso trilhado na busca do emagrecimento, motivadas pelos sintomas imediatos do excesso de peso ou por profissionais de saúde e apoiadas por amigos e familiares, as mulheres se 
submeteram às mais diferentes modalidades para redução de peso. Com exceção da cirurgia bariátrica, as informantes citaram diversas estratégias visando ao emagrecimento, transitando entre tratamentos com profissionais de saúde e uso de medicamentos; tratamento sem auxílio desses profissionais e com utilização de dietas indicadas por amigas ou veiculadas na mídia.

Énecessárioquehaja maiorcompreensãoevalorizaçãodamultidimensionalidade inerente aos quadros de obesidade, em especial a dimensão simbólica, relativa aos significados, percepções e opiniões que configuram a constituição da subjetividade e singularidade deste grupo de pessoas que vivenciam o excesso de peso e buscam atendimento nos serviços públicos (ou privados) de saúde. Tal compreensão é fundamental para a proposição de planos e estratégias de atendimento no campo das políticas de saúde e na promoção da alimentação saudável.

\section{Referências}

BOLTANSKI, L. La découverte de la maladie: la diffusion du savoir medical. Paris: Centre de Sociologie Européenne, 1968.

BOLTANSKI L. As classes sociais e o corpo. Rio de Janeiro: Graal; 1979.

BOSI, M. L. M. Trabalho e subjetividade: cargas e sofrimento na prática da nutrição social. Revista de Nutriçāo, Campinas, v. 13, n. 2, p. 107-115, 2000.

BRASIL. Ministério da Saúde. Conselho Nacional de Saúde. Comissão Nacional de Ética em Pesquisa. Resolução no 196, de 10 de outubro de 1996. Pesquisa envolvendo seres humanos. Brasília, 1996.

BRASIL. Ministério da Saúde. Secretaria de Atenção à Saúde. Departamento de Atenção Básica. Obesidade .Brasília: da Saúde, 2006 b. 108 p. (Cadernos de atenção básica, n. 12).

CARVALHO, Liliane B.; FREIRE, José C.; BOSI, Maria Lúcia M. Alteridade radical: implicações para o cuidado em saúde. Physis, v. 19, n. 3, p. 849-865, 2009.

FERREIRA, J. O corpo sígnico. In: ALVES, P. C.; MINAYO, M.C. de S. (Org.). Saúde e doença: um olhar antropológico, Rio de Janeiro: Fiocruz, 1994. p. 101-111.

FERREIRA, V.A. Obesidade e pobreza: o aparente paradoxo. Um estudo com mulheres da Favela da Rocinha, Rio de Janeiro, Brasil. Cad. Saúde Pública, v. 21, n. 6, p.1792-1800, 2005.

GALLO, M.F. et al. Combination estrogen-progestin contraceptives and body weight: systematic review of randomized controlled trials. Obstet Gynecol. v. 103, n. 2, p. 359-73, 2004.

GODOY, Maria Gabriela C.; BOSI, Maria Lúcia M.. In: BOSI, M.L.M.; MERCADO, F.J. (Org.) Pesquisa qualitativa de serviços de saúde. Rio de Janeiro: Vozes, 2004. p. 223-277. 
GOFFMAN, E. Estigma: notas sobre a manipulação da identidade deteriorada. Rio de Janeiro: Livros Técnicos e Científicos, 1988. 160p.

GASPAR, F.M.P. Obesidade e trabalho: histórias de preconceito e reconhecimento vividas por trabalhadores obesos. São Paulo: Vetor, 2003. 136p.

JORDÃO, I.S.C.; KAC, G. Determinantes da retenção de peso pós-parto segundo a cor da pele em mulheres do Rio de Janeiro Revista panamericana de salud pública, v. 18, n. 6, p. 403-411, 2005.

LEWIS, Stephen T.; PUYMHROECK, Marieke Van. Obesity-stigma as a multifaceted constraint to leisure. Journal of leisure research, v. 40, n. 4, p. 574-588, 2008.

MANCINI; HALPERN. Tratamento farmacológico da obesidade. Arq bras Endocrinol metab, São Paulo, v. 46, n. 5, p. 497-512, 2002.

MATTOS, R.S. Nasci de novo: sobrevivendo ao estigma da gordura - um estudo de caso sobre obesidade. 2008. 248p. Dissertação (Mestrado em Saúde Coletiva) - Instituto de Medicina Social, Universidade do Estado do Rio de Janeiro, Rio de Janeiro, 2008.

PINTO, Maria Soraia. Elas têm fome de quêe? Obesidade em mulheres da comunidade da Expectativa Sobral-CE. 2007. 56p. Monografia (Especialização com caráter de Residência Multiprofissional em Saúde da Família) - Universidade Estadual Vale do Acaraú / Escola de Formação em Saúde da Família Visconde de Sabóia, Sobral, 2007.

TEIXEIRA, Márcia J. Fome de vida: vivências e percepções de mulheres obesas portadoras do transtorno da compulsão alimentar periódica. 2003. 160p. Dissertação (Mestrado em Saúde Coletiva) - Universidade Federal do Rio de Janeiro, Rio de Janeiro, 2003.

WANG, S.S.; BROWNELL, K.D.; WADDEN, T.A The influence of the stigma of obesity on overweight individuals. International journal of obesity n. 28, p. 1333-1337, 2004. 
Beyond their weight/thoughts: perceptions and experiences of obese women assistant of public health services of a municipality of Northeastern Brazil

Exploratory qualitative research with critical hermeneutic-phenomenological approach, seeking to understand the experiences and perceptions about obesity among users of a Family Health Center. The strategy adopted was a link between the in-depth interviews and observation with a purposive sample consisted of eight obese women attending a Family Health Centre located in Fortaleza, Ceará (Brazil). The categorization of empirical data indicated four thematic areas of analysis: 1) Self-perception of body, 2) Ethno-etiology of obesity, 3) Stigma and its impact on different domains of life, 4) Track the paths of Healing. Although aware of this excessive weight on their bodies, in another terminology, women do not identify themselves as obese. Clinical symptoms and difficulties in developing daily activities as well as the discourse of health professionals were important triggers the perception of obesity. On these women, the stigma of obesity weighs heavily, bringing repercussions on their daily lives, influencing social relationships, family and work. The participants consider obesity a disease amenable to cure, and are strongly influenced by their own actions. The concept of healing for the interviewee does not seem to be linked to achieving a lean body, thus, aimed at reducing drug use and the ability to perform daily activities. To monitor this group in primary care, it is necessary to add the aspect biomedical perspective of those who experiment obesity.

> Key words: Qualitative research, women, obesity, stigma. 